\title{
Lemahnya Pengendalian Internal Berdamapak Terjadi Mark Up Biaya Pengawalan PT ALRSY
}

\author{
Andi Martias \\ Universitas Bina Sarana Informatika \\ Email: andi.aim@bsi.ac.id
}

\begin{abstract}
Internal audit can be interpreted as an audit and assessment activity in a company as a whole, which aims to help all levels of management in carrying out their responsibilities effectively through the provision of useful advice to improve performance at each level of management. The method of this research is a qualitative approach. To ensure the independence, objectivity and quality of the process, an internal auditor is needed as a facilitator in the process which will also independently report the results to the company's management and also as a basis for control. As a logistics company, companies often receive orders to ship items for project needs such as heavy equipment, spare parts, etc., to ensure that there are no disturbances on the road, the company usually requests police escort services. From the police there is no official tariff to be paid because of its assistance. Because there is no official tariff, it causes irregularities in practice. This study analyzes the weaknesses that occur due to a lack of internal controls. . From the description and analysis discussed earlier, conclusions can be taken that must be considered to avoid the occurrence of fraud cases again is the nature of prudence (overconfidence in colleagues, communication systems that have not been effective, low honesty, integrity and loyalty of employees).
\end{abstract}

Keywords: Internal Control.Internal Auditing,Fraud

Martias, A. (2019). Lemahnya Pengendalian Internal Berdamapak Terjadi Mark Up Biaya Pengawalan PT ALRSY. Moneter, 6(2), 25-38.

\section{PENDAHULUAN}

Audit Internal dapat diartikan sebagai aktivitas pemeriksaan dan penilaian dalam suatu perusahaan secara menyeluruh, yang bertujuan membantu semua tingkatan manajemen dalam melaksanakan tanggung jawabnya secara efektif melalui pemberian saran yang berguna untuk memperbaiki kinerja disetiap tingkatan manajemen. Metode penelitian ini adalah pendekatan kualitatif berdasarkan historical experience dan observasi.

Evolusi profesi internal auditing, saat ini menunjukan dinamika yang mengarah pada perkembangan melaju sangat cepat seiiring dengan perkembangan jaman pada era globalisasi (Hiro Tugiman, 2014) Dengan kondisi seperti ini evolusi membuat auditor internal turut berperan dalam implementasi Good Corporate Government (GCG) di perusahaan maupun di pemerintahan. Dalam perkembangannya penekanan dan mekanisme internal audit telah bergeser (berubah). Pada masa lalu fokus utama peran internal auditor adalah sebagai 'watchdog' dalam perusahaan, sedangkan pada masa kini dan mendatang proses internal auditing modern telah bergeser menjadi 'konsultan intern' (internal consultant) yang memberi masukan berupa pikiran-pikiran untuk perbaikan (improvement) atas sistem yang telah ada serta berperan sebagai katalis (catalyst). Fungsi internal auditor sebagai 'watchdog' membuat perannya "kurang disukai" kehadirannya oleh unit organisasi lain. Hal ini mungkin merupakan konsekuensi logis dari profesi internal auditor yang tugasnya memang tidak dapat dilepaskan dari fungsi audit (pemeriksaan), bahwa antara pemeriksa (auditor) dan pihak yang diperiksa (auditee) berada pada posisi yang saling berhadapan (Hogan, 2014).

Meningkatnya persaingan usaha dalam era globalisasi sekarang ini menuntut perusahaan agar dalam pelaksanaan usahanya dapat beroperasi secara efektif dan efisien.

Dalam menjalankan bisnisnya, setiap perusahaan memiliki resiko kerugian keuangan yang pada akhirnya akan mempengaruhi bisnisnya karena menjadikan unsur biaya menjadi tinggi. Biaya tinggi akan membuat perusahaan sulit bersaing karena saat ini orang menjadi semakin pemilih dimana selalu berusaha mencari produk atau jasa yang bagus dengan harga yang murah (Blanchhard, 2013).

Di sinilah peran Pengendalian Internal atau Internal Auditor dibutuhkan karena tugasnya adalah membantu manajemen dalam hal-hal sebagai berikut:

1. Menilai efisiensi dan efektivitas kinerja manajemen

2. Memberikan saran yang konstruktif untuk meningkatkan kinerja

3. Memonitor kualitas, integritas dan keandalan proses pelaporan transaksi keuangan. 
Keterlibatan internal auditor dalam aktivitas operasional sehari-hari termasuk dalam proses pelaporan transaksi keuangan dan sistem pengendalian intern memberi kesempatan internal auditor untuk melakukan penilaian secara berkala dan menyeluruh atas aspek-aspek operasional perusahaan yang memiliki risiko tinggi (Martias, 2017).

Standar Profesi Audit Internal (1210.2) menyatakan bahwa internal audit harus memiliki pengetahuan yang memadai untuk dapat mengenali, meneliti dan menguji adanya indikasi kecurangan. SIAS No. 3 menyatakan bahwa internal audit diwajibkan untuk mewaspadai kemungkinan terjadinya ketidak wajaran penyajian, kesalahan, penyimpangan, kecurangan, inefficiency, konflik kepentingan dan ketidakefektifan pada suatu aktivitas perusahaaan.

Berdasarkan paparan yang telah dijelaskan diatas diketahuai pada PT.ALARSY masih terdapat kelemahan akan kesadaran atas semua faktor penting yang dapat mempengaruhi pencapaian tujuan sehingga memungkinkan manajemen dari semua tingkat melakukan penyesuaian-penyesuaian (menciptkan kontrol) yang dibutuhkan.

Lemahnya pengendalian internal akan berdampak pada risiko operasional perusahaan dimana akan berpengaruh terhadap seluruh aktivitas yang ada di dalam perusahaan. Hal inilah yang menjadi rumusan masalah untuk melakukan penelitian "Lemahnya Pengendalian Internal Berdampak Terjadi Mark Up Biaya Pengawalan PT ALRSY”. PT.ALARSY adalah perusahaan bergerak dalam bidang logistik dimana untuk area Kalimantan berpusat di Balikpapan dan mempunyai kantor perwakilan di: Samarinda, Batu Kajang, Tarakan, Tanjung Redep, Sangatta, Banjarmasin, Batu Licin, Tanjung Adaro, Satui, Senakin, Pontianak dan Pangkalan Bun. Dengan melihat semua aspek fungsi di internal control, penulis ingin mengamati lebih mendalam mengenai sejauh mana kemajuan lembaga ini dalam menjalankan fungsinya sehingga dapat berpartisipasi secara maksimal pada pembangunan perusahaan demi mewujudkan tujuan perusahaan yaitu kemakmuran dan kesejahteran hidup karyawan. Penulis ingin mengetahuai sejauhmana peran pengawasan internal atau internal auditor dalam melaksanakan fungsinya yang merupakan bagaian dari unit kerja perusahaan. Bila lemahnya fungsi pengendalian akan berakibat berbagai risiko yang akan berpengaruh terhadap aktivitas dan tujuan manajeman atau perusahaan tidak bisa tercapai.

\section{Internal Audit}

Perkembangan profesi internal auditing, dewasa ini melaju sangat cepat seiiring dengan perkembangan jaman pada era globalisasi. Definisi / pengertian internal auditing juga mengalami perubahan dari waktu ke waktu.

a. Pengertian Menurut Sawyer (The Practice of Modern Internal Auditing”, The Institute of
Internal Auditors, 2010) “ Internal auditing is an independent appraisal function establised within an organization to examine and evaluate its activities as a service to organization"

b. (Internal audit adalah suatu fungsi penilaian independen yang dibentuk dalam suatu organisasi untuk mengkaji dan mengevaluasi aktivitas organisasi sebagai bentuk jasa yang diberikan bagi organisasi).

c. Pengertian Menurut Institute of internal Auditor (IIA, 2012) "Internal auditing is an independent , objective assurance and consulting activity designed to add value and improve an organization's operations. It helps an organization accomplish its objective by bringing a systematic, disciplined approach to evaluate and improve the effectiveness of risk management, control and governance process".

d. Internal audit adalah suatu aktivitas independen, yang memberikan jaminan keyakinan serta konsultasi yang dirancang untuk memberikan suatu nilai tambah serta meningkatkan kegiatan operasi organisasi. Internal auditing membantu organisasi dalam usaha mencapai tujuannya dengan cara memberikan suatu pendekatan disiplin yang sistematis untuk mengevaluasi dan meningkatkan keefektivan manajemen resiko, pengendalian dan proses pengaturan dan pengelolaan organisasi).

Committee of Sponsoring Organization (COSO) dalam (Moeller, 2012) memberikan definisi mengenai pengendalian internal sebagai berikut: "Internal control is a process, affected by an entity's board of directors, management, and other personnel, designed to provide reasonabl assurance regarding the achievement of objectives in the following categories:

a. Effectiveness and efficiency of operations.

b. Reliability of financial reporting.

c. Compliance with applicable laws and regulations. "

Pengendalian internal dipengaruhi atau dilaksanakan oleh semua karyawan baik direktur maupun karyawan dengan level terendah sekalipun dalam sebuah perusahan. Dengan pengendalian internal yang baik maka perusahaan tersebut dapat dikatakan memiliki efektivitas dan efisiensi dalam operasional, memiliki laporan keuangan yang handal dan menjamin bahwa perusahaan mematuhi peraturan dan hukum yang berlaku (Sawyre, 2006).

\section{Paradigma Baru Internal Audit}

Internal Audit (pemeriksaan intern) adalah pemeriksaan yang dilakukan oleh bagian internal audit perusahaan, baik terhadap laporan keuangan dan catatan akuntansi perusahaan, maupun ketaatan terhadap kebijakan manajemen puncak yang telah ditentukan dan ketaatan terhadap peraturan 
pemerintah (regulator) misalnya peraturan dibidang perpajakan, pasar modal, lingkungan hidup, perbankan, asuransi, perindustrian, investasi dan lain-lain.Karena yang melakukan internal audit (disebut internal auditor) adalah pegawai perusahaan sendiri (orang dalam perusahaan), maka banyak pihak yang menganggap bahwa internal auditor tidak independen (Efendy, 2014). Fungsi konsultan bagi internal auditor merupakan peran yang relatif baru. Peran konsultan membawa internal auditor untuk selalu meningkatkan pengetahuan baik tentang profesi auditor maupun aspek bisnis, sehinga dapat membantu manajemen dalam memecahkan suatu masalah. Kemampuan untuk merekomendasikan pemecahan suatu masalah (problem solver) bagi internal auditor dapat diperoleh melalui pengalaman bertahun-tahun melakukan audit berbagai fungsi di perusahaan (Handoko, 2009).

Pada saat ini, konsultasi internal merupakan aktivitas yang sangat dibutuhkan oleh manajemen yang perlu dilakukan oleh internal auditor. Selain sebagai konsultan, internal auditor harus mampu berperan sebagai katalisator. Katalis adalah suatu zat yang berfungsi untuk mempercepat reaksi namun tidak ikut reaksi. Peran auditor internal sebagai katalisator yaitu memberikan jasa kepada manajemen melalui saran-saran yang bersifat konstruktif dan dapat diaplikasikan bagi kemajuan perusahaan namun tidak ikut dalam aktivitas operasional di perusahaan. Ruang lingkup (scope) kegiatan audit semakin luas, pada saat ini tidak sekedar audit keuangan (financial audit) dan audit ketaatan (compliance audit), tetapi perhatian lebih ditujukan pada semua aspek yang berpengaruh terhadap kinerja perusahaan dan pengendalian manajemen serta memperhatikan aspek resiko bisnis/manajemen. Perubahan orientasi audit dari teknik-teknik pengendalian intern ke arah pengendalian bisnis perusahaan yang didasarkan atas risiko bisnis (business risk) atau rmanajemen risiko (risk management) ini akan terus berjalan seiring dengan kebutuhan perusahaan yang semakin kompleks di masa mendatang. Oleh karena itu saat ini berkembang pendekatan teknik audit dalam internal auditing yang berbasiskan risiko (risk based internal auditing) (Reksohadiprojo, 2010).

\section{Pengertian Fraud}

Dalam lingkungan Auditor istilah Fraud adalah kata yang sudah tidak asing lagi. Fraud dapat didefinisikan sebagai "suatu penyimpangan atau perbuatan melanggar hokum (illegal act) yang dilakukan dengan sengaja untuk tujuan tertentu. Fraud dapat dicegah denan melakukan pengawasan dan pengendalian internal yang baik. Akan tetapi semua system, aturan dan prosedur yang dibuat akan sangat dipengaruhi oleh manusia yang menjalankannya (Ningrat, 2010).

The Institute of Internal Auditor (IIA) menyebutkan kecurangan adalah meliputi serangkaian tindakan- tindakan tidak wajar dan illegal yang sengaja dilakukan untuk menipu. Tindakan tersebut dapat dilakukan untuk keuntungan individu atau kerugian organisasi.

Dalam kaitan dengan mengidentifikasikan kecurangan yang dapat terjadi maka auditor harus mampu melakukan hal-hal seperti berikut ini:

a. Mengkaji system pengendalian intern untuk menilai kekuatan dan kelemahannya

b. Mengidentifikasi potensi kecurangan berdasarkan kelemahan yang ada pada system pengendalian intern.

c. Mengidentifikasi hal-hal yang menimbulkan tanda tanya dan transaksi-transaksi diluar kewajaran

d. Membedakan faktor kelemahan dan kelalaian manusia dari kesalahan yang bersifat fraud.

e. Berhati-hati terhadap prosedur, praktik dan kebijakan manajemen

\section{Jenis dan pelaku fraud}

a. Employee embezzlement (occupational fraud). Kecurangan yang dlakukan pegawai karena jabatan atau keduidukannya dalam organisasi, biasanya untuk keuntungan pribadi. Misalnya: membuat transaksi fiktif, membuat/merubah dokumen untuk keuntungan pribadi

b. Management fraud, Kecurangan yang dilakukan oleh manajemen bisa untuk kepentingan pribadi maupun perusahaan. Misal: merekayasa laporan keuangan, membuat kontrak fiktif.

c. Pihak luar, Kecurangan yang dilakukan oleh pelanggan atau pemasok, misalnya membuat penagihan ganda, menjual barang dengan harga tinggi dibanding kualitas barang.

\section{Faktor yang memicu fraud}

Dalam melakukan pendeteksian terhadap kecurangan tidak dapat dilepaskan dari pengetauan mengenai hal-hal yang menjadi pemicu terjadinya fraud. Hal-hal yang menjadi pendorong seseorang atau kelompok orang melakukan kecurangan dipengaruhi 3 (tiga) unsur pendukung yang juga biasa disebut Fraud Triangle adalah:

a. Adanya Tekanan (perceive pressure)

Faktor-faktor yang dapat meningkatkan tekanan antara lain:

1) Masalah keuangan, seperti tamak, hidup melebihi kemampuan, banyak hutang, kebutuhan tak teduga

2) Sifat buruk, seperti penjudi, peminum, pecandu narkoba

3) Hubungan dengan pekerjaan, seperti kurang mendapat perhatian, kondisi kerja yang buruk

4) Lain-lain, seperti tekanan dari keluarga

b. Adanya kesempatan (perceive opportunity)

Faktor-faktor yang dapat meningkatkan adanya peluang seseorang berbuat kecurangan antara lain: 
1) Sistem pengendalian intern yang lemah

2) Tidak mampu menilai kualitas kerja

3) Kurang atau tidak adanya akses terhadap informasi

4) Gagal mendisiplinkan atau memberikan sanksi pada pelaku kecurangan

5) Lalai, apatis

6) Kurang atau tidak adanya audit trail

c. Adanya alasan pembenaran (rationalization)

Faktor-faktor yang mendorong seseorang mencari pembenaran atas tindakannya melakukan kecurangan, antara lain:

1) Mencontoh atasan atau teman sekerja

2) Merasa sudah berbuat banyak kepada perusahaan

3) Menganggap bahwa yang diambil tidak seberapa

4) Dianggap meminjam, pada waktunya akan dikembalikan

Dengan bertitik tolak dari tiga elemen (fraud tiangle) mengapa seseorang melakukan kecurangan, dapat disimpulkan ada dua unsur yang menentukan terjadinya kecurangan, yaitu manusia dan sIstem pengendalian dalam organisasi (Yayasan Pendidikan Internal Audit, 2008).

\section{GONE Theory}

Merupakan singkatan Greed (keserakahan), Opportunity (kesempatan), Need (kebutuhan) dan Exposure (pengungkapan) dimana faktor greed dan need berhubungan dengan individu (pelaku kecurangan) sedangkan opportunity dan exposure berhubungan dengan organisasi (korban perbuatan kecurangan).

Faktor-faktor tersebut dikelompokkan ke dalam faktor generik dan faktor individu.

\section{Faktor Generik}

Faktor ini berada dalam pengendalian organisasi (perusahaan) yang mencakup:

a. Kesempatan (opportunity)

b. Kesempatan melakukan kecurangan tergantung pada kedudukan pelaku terhadap obyek kecurangan. Kesempatan untuk melakukan kecurangan tidak dapat dihilangkan secara keseluruhan. Usaha untuk menghilangkan kesempatan terjadinya kecurangan secara keseluruhan menjadi tidak ekonomis dan tidak produktif selama perusahaan tersebut masih memiliki asset, dimana asset tersebut diperdagangkan, mengalir dan ada dalam pengendalian pihak lain seperti karyawan, pembeli dan penjual.

c. Kemungkinan bahwa kecurangan akan dapat diketahui dan diungkapkan (exposure)

d. Kondisi saat ini ada kecendurangan makin tipisnya kepekaan seseorang/sekelompok orang terhadap kecurangan yang terjadi disekelilingnya. Hal ini mungkin dipicu oleh kekhawatiran mereka khususnya berkaitan dengan perlindungan terhadap pihak-pihak yang mengungkapkan terjadinya kecurangan tersebut. Apabila kondisi ini terus terjadi, maka secara logika kecurangan makin merajalela, karena pelaku kecurangan tersebut merasa bahwa kecurangan apapun yang mereka lakukan tidak ada pihak lain yang berani mengungkapkannya,

e. Sanksi yang dikenakan kepada pelaku jika tertangkap dan perbuatannya terungkap (exposure)

Terungkapnya kecurangan belum cukup untuk mencegah terulang kembalinya kejadian tersebut di masa yang akan datang. Oleh karena itu harus ada sanksi atas perbuatan tersebut yang jelas. Tegas dan diterapkan sesuai dengan aturan yang berlaku. Suatu perusahaan yang ingin melindungi assetnya harus memiliki kebijkan (policy) yang jelas mengenai sifat dan besarnya sanksi terhadap pelaku kecurangan seperti:

a. Siapapun yang terlibat kecurangan akan dipecat

b. Semua kecurangan akan dilaporkan kepada pihak yang berwenang

\section{Faktor Individu}

Faktor ini melekat pada diri seseorang yang melakukan kecurangan. Secara umum faktor ini dapat dikategorikan menjadi dua yaitu:

a. Moral yang berhubungan dengan keserakahan (greed).

b. Keserakahan berhubungan dengan atribut seseorang. Sebagaimana dengan atribut lainnya yang ada dalam diri manusia seperti kejujuran, integritas, loyalitas dan sebagainya adalah sulit untuk mengetahui apakah seseorang memilik atribut serakah ini atau tidak.

c. Motivasi yang berhubungan dengan kebutuhan (need).

Salah satu yang menjadi penyebab seseorang atau sekelompok orang melakukan kecurangan adalah berhubungan dengan kebutuhan ekonomi. Disamping itu kecurangan juga dapat disebabkan oleh adanya perasaaan ketidakpuasan atas kebijakan yang ditetapkan oleh manajemen, balas dendam dan tantangan.

\section{Sawyer Theory}

Menurutnya faktor pemicu fraud ada tiga yang bersifat kolektif dan dapat terjadi dengan tingkatannya yang berbeda-beda yaitu:

a. Situasi akan kebutuhan

b. Disebabkan oleh alasan keuangan karena pengeluaran atau kerugian uang yang tidak dapat ditutupi oleh sumber daya keuangan yang normal dari individu tersebut. Misaalnya: keluarga sakit, suka berjudi, perselingkuhan, kerugian usaha atau investasi, kecelakaan. 
c. Lingkungan yang mengundang terjadinya penggelapan

d. Hal ini biasanya merupakan situasi dimana lemah nya atau tidak adanya kontrol atau dimana terdapat kontrol tetapi tidak berfungsi. Seringkali kondisi ini terungkap melalui sutuasi yang tidfak disengaja ketika seseorang karena suatu kesalahan menyadari bahwa ia telah menerima uang secara tidak benar, meskipun uang tersebut ia peroleh secara tidak sengaja dan bahwa kontrol yang seharusnya mencegah kejadian tersebut tidak ada atau tidak berfungsi.

e. Karakteristik perilaku seseorang

f. Kedua kondisi diatas dapat terjadi namun jika individu tersebut memiliki sifat jujur yang tinggi, kecurangan tidak akan dilakukan. Jika unsur pertama ditambah unsur kedua terjadi dapat pula merubah perilaku dasar seseorang untuk menjauhi hal-hal seperti itu dan membuka pintu terjadinya penyelewangan.

Auditor Internal harus selalu mengingat faktorfaktor yang mendorong terjadinya fraud dan menyadari bahwa fraud dapat terjadi dari tingkatan rendah hingga tingkatan tinggi.

\section{Mencegah terjadinya fraud}

Dengan bertitik tolak pada penyebab mengapa seseorang melakukan kecurangan, dapat disimpulkan bahwa ada dua unsur yang menentukan terjadinya kecurangan yaitu manusia dan sistem pengendalian internal.

Hal diatas dapat dilakukan dengan:

a. Membangun budaya jujur, terbuka dan pemberian bantuan

Untuk melakukannya dapat dimulai dengan halhal sebagai berikut:

1) Penerimaan karyawan yang jujur

2) Menciptakan lingkungan/suasana kerja yang positif

3) Penerapan kode etik dan aturan perilaku

4) Pemberian program bantuan bagi karyawan yang membutuhkan

b. Membangun sistem pengendalian intern yang efisien dan efektif

Committee of Sponsoring Organization of the Treadway Commission (COSO) menetapkan 5 (lima) komponen struktur pengendalian intern yang harus dilaksanakan, yaitu:

1) Lingkungan pengendalian (control environment)

Adalah tindakan, kebijakan dan prosedur yang merefleksikan seluruh sikap dari top manajemen sampai karyawan terbawah terhadap nilai-nilai integritas, kejujuran, kesetiaan, kedisplinan, dedikasi dan loyalitas.

2) Penilaian resiko (risk assessment)

Perusahaan harus menetapkan tujuan dengan memperhatikan aspek keuangan serta kegiatan lainnya agar beroperasi secara terkoordinasi dengan mengidentifikasikan, menganalisa dan mengelola risiko yang diperkirakan akan terjadi.

3) Aktivitas pengendalian (control activities) Adalah kebijakan dan prosedur yang dibangun oleh manajemen untuk mencapai tujuan laporan keuangan yang obyektif. Aktivitas pengendalian dapat digolongkan dalam pemisahan tugas, sistim otorisasi, pengecekan independen, pengamanan fisik dan pendokumentasian dan pencatatan yang cukup.

4) Informasi dan komunikasi (information and communication)

Ketentuan-ketentuan dan peraturan serta kode etik mengenai apa yang boleh dan tidak boleh dilakukan karyawan harus dikomunikasikan ke seluruh jajaran dalam perusahaan.. Komunikasi harus secara konsisten dilakukan dalam berbagai forum seperti pelatihan, diskusi, rapat dan lainlain.

5) Pemantauan (monitoring)

Pemantauan kegiatan pengendalian internal secara periodik harus dipantau oleh manajemen yang meliputi penilaian dari kualitas kinerja pengendalian internal untuk menentukan apakah operasi pengendalian memerlukan modifikasi atau perbaikan.

Dalam meminimalkan risiko yang akan timbul perusahaan harus memastikan fungsi system pengendalian internal sangat diperlukan berserta jajaran manajemen sehingga apa yang menjadi tujuan yang diharapkan bisa tercapai. Untuk mewujudkan tujuan ini melalui program yang di jalankan oleh Divisi Pengendalian Internal yang tidak laian adalah Internal Auditor, maka unit kerja tersbut membutuhkan pula sumber daya manusia yang handal, berkualitas guna menjalankan segala bentuk aktivitas yang ada dalam perusahaan ini.

Banyak kendala-kendala yang masih dihadapi oleh manusia sebagai sumber daya dalam proses pembangunan di perusahaan. Masalah-masalah terrsebut dapat diidendifikasi sebagai berikut; politik, budaya, sumber daya manusia, peraturan perundang-undangan kepegawaian yang merupakan salah satu hambatan besar bagi auditor dalam melaksanakan tugasnya. Masalah yang dapat dirumuskan oleh penulis di sini adalah sejauhmana peranan pengendalian internal dalam pelaksanaan tugas di PT ALARSY. Lemahnya pengendalian akan berdampak berbagai risiko yang akan timbul yang mengakibatakan aktivitas dan tujuan manajeman atau perusahaan tidak bisa tercapai.

Dengan menganalisa peran pengawasan internal dalam melaksanakan tugasnya guna mencapai tujuan manajemen yang diharapkan, diharapkan bisa bermanfaat untuk manajemen perusahaan sebagai 
dasar penentuan corrective action dalam proses aktivitas perbaikan kinerja. Dengan berorientasi pada meminimalkan risiko-risiko yang akan timbul di kemudian hari. Selain itu juga dengan mengetahui cara proses pengawasan yang baik dan pendekatan fungsi pengawasan internal yang maksimal diharapkan tidak ada kekhawatiran pada auditee yang merupakan entitas yang akan diaudit untuk tidak menjadi momok ketakutan namun berfunsi sebagai konsultan dalam menilai sejauh mana risiko harus di mitigasi dalam prosesnya.

\section{METODOLOGI PENELITIAN}

Penelitian dilakukan dengan cara observasi di kantor pusat kedalam proses di PT. ALARSY dan sampel data Area Kalimantan. PT ALARSY merupakan perusahaan Perusahaan bergerak dalam bidang logistik dimana untuk area Kalimantan berpusat di Balikpapan dan mempunyai kantor perwakilan di: Samarinda, Batu Kajang, Tarakan, Tanjung Redep, Sangatta, Banjarmasin, Batu Licin, Tanjung Adaro, Satui, Senakin, Pontianak dan Pangkalan Bun. Penelitian ini merupakan studi peristiwa pada perusahaan logistic yaitu melihat proses pengendalian internal terhadap proses pengelolaan system pada perusahaan PT ALRSY. Hal ini dimaksudkan untuk menguji apakah terdapat pengaruh tujuan perusahaan maupun managemen. Studi peristiwa dalam penelitian ini dilakukan dengan menganalisa kualitatif berdasarakan hasil audit internal dan survey observasi.

Dalam rangka mlaksanakan tugasnya, pengawasan internal atau internal auditor dituntut untuk selalu menjaga dan mencapai tujuan audit. Dalam mencapai hal tersebut auditor memperhitungkan berbagai faktor yang mempengaruhi dalam tugasnya. Pada PT ALARSY fungsi pengendalian internal sudah melaksanakan tugasnya dengan baik sehingga tidak terdapat kendala dalam pelaksanaa fungsinya namun masih terdapat beberapa proses yang tidak ter-capture sehingga berdampak pada beberapa proses yang bisa menimbulkan kerugian secara finansial bagi perusahaan.. Hal ini terlihat dari beberapa proses Mark Up di PT ALARSY. Hal ini timbul karena belum maksimalnya aktivitas yang dijalan oleh pengendalian internal secara contro fuctionl. Merupakan komunikasi formal yang berhubungan dengan kegiatan-kegiatan operasional. Adapun tugas dan tanggung jawab secara garis besar adalah sebagai berikut:

\section{Senior Manager}

Bertanggung jawab serta memastikan semua fungsi keuangan, operasional, marketing dan HRD berjalan dengan baik.

2. Finance Accounting (FA) Manager

Bertanggung jawab atas semua aktivitas keuangan agar dapat mendukung kegiatan operasional perusahaan termasuk melakukan proses pengeluaran uang, melakukan penagihan kepada pelanggan sekaligus melakukan monitoring terhadap saldo piutang usaha.

3. Human Resources and General Affair (HRGA) Manager

Mempunyai tanggung jawab atas proses kepegawaian seperti rekrutmen, training,kesehatan juga pengurusan perjalanan dinas karyawan seperti pemesanan tiket dan hotel, memastikan semua kebutuhan karyawan akankebutuhan pekerjaan bisa terpenuhi.

4. Marketing Manager

Bertanggung jawab terhadap kegiatan sales dan marketing di area Kalaimantan, menjaga hubungan dengan pelanggan.

5. Operasional Manager

Bertanggung jawab atas semua kegiatan operasional agar dapat berjalan lancar.

Dalam menjalankan kegiatan operasional perusahaan, Operasional Manager membagi dalam tiga aktivitas yaitu:

1. Air Freight (sky express) untuk semua kegiatan pengiriman barang melalui udara. Dengan menawarkan pengiriman sehari di berbagai kota di Indonesia untuk dokumen, paket dan kargo. Adapun pengiriman ekspres melalui jalur udara terbagi menjadi 3 bagian, yaitu :

a. Same Day Service adalah Kiriman hari ini diterima di kota tujuan pada hari yang sama (sebelum jam 24.00). Same Day Service sudah termasuk asuransi kerusakan dan kehilangan barang sampai dengan Rp 4 juta dan pemberian proof of delivery kepada Pengirim. Eka Sari Lorena memberikan jaminan uang kembali.

Hari layanan : Senin - Jumat Batas waku terima barang (Cut of Time) : Jam 11.00. Jangkauan : Hanya kota-kota yang terdaftar di price list, perlunya koordinasi (Pre Alert) dengan kota tujuan.

b. Over Night Service adalah pengiriman hari ini diterima keesokan harinya sebelum jam 18.00. Over Night Service sudah termasuk Asuransi kerusakan dan kehilangana barang maksimum Rp 2 juta. Kami memberikan jaminan uang kembali. Hari layanan : Senin - Jumat Batas waktu terima barang (Cut of Time) adalah Jam 12.00. Jangkauan hanya kota-kota yang terdaftar di price list. Perlunya koordinasi (Pre Alert) dengan Kota tujuan.

c. Reguler Service Premium adalah Pengiriman 2 - 5 hari ke kota-kota besar atau kota satelit di seluruh Indonesia. Pengiriman Barang berharga dapat dilindungi dari resiko rusak atau hilang dengan Memanfaatkan jasa Asuransi (menambah biaya Asuransi). Hari Layanan : Senin - Minggu Batas waktu terima barang (Cut of Time) adalah Jam 20.00. 
Jangkauan hanya kota-kota yang terdaftar di price list. Perlunya koordinasi (Pre Alert) dengan Kota tujuan. Pre Alert digunakan untuk barang yang butuh penanganan khusus, maka harus ada pemberitahuan awal (pre alert) kepada kantor cabang atau agen atau perwakilan kota tujuan.

Ketentuan Pengiriman untuk pengiriman via udara adalah sebagai berikut : Berat minimal : $1 \mathrm{Kg}$ Ketentuan $\mathrm{Kg}: 0.1-1.00=$ $1 \mathrm{~kg} 1.1-2.00=2 \mathrm{~kg} 2.1-3.00=3 \mathrm{~kg}$, dst Wajib Asuransi : Bila barang yang dikirim nilainya melebihi dari nilai asuransi yang ditetapkan. SDS .> 4 Juta ONS > 2 Juta RSP > 1 Juta.

2. Warehouse yang berfungsi sebagai tempat transit barang sebelum dikirimkan ke pelanggan. Dalam proses perhitungan biaya peroleha dibayar dimuka ditentukan dengan menggunakan metode masuk pertama keluar pertama (FIFO).

3. Fleet (road express) untuk melakukan seluruh proses pengiriman barang melalui jalur darat. Proses pengiriman ekspres melalui jalur darat terbagi menjadi 3 bagian:

a. Reguler Express adalah Layanan cepat melalui transportasi darat dengan harga kompetitif dan ekonomis untuk pengiriman dengan jangka waktu yang tidak terlalu ketat (Less Time Sensitive) dengan minimal berat paket $2 \mathrm{~kg}$. Regular Express terdiri dari pelayanan
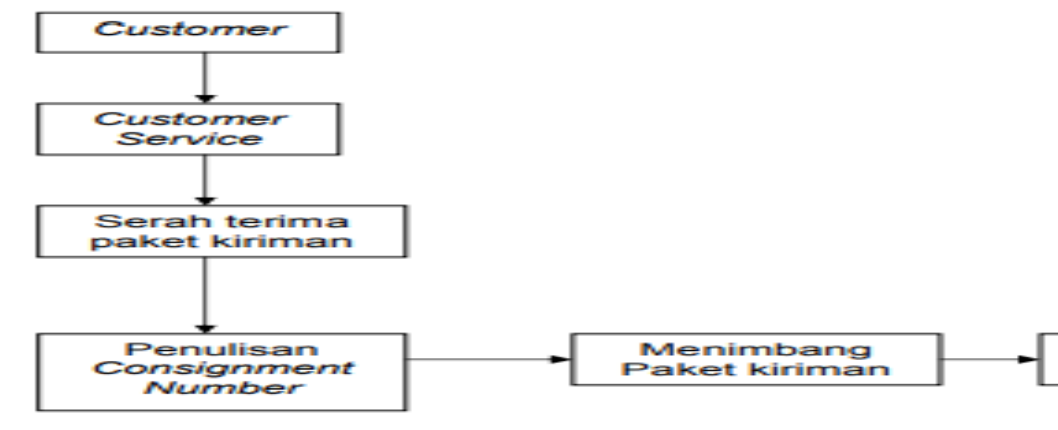
Penghitungan harga
berdasarkan berat $+$

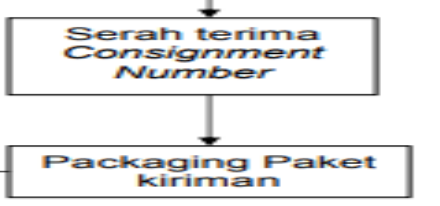

Gambar 1. Alur Proses Logistik pengiriman Dokumen, Paket, dan Kargo, yang diperhitungkan sesuai berat pengirimannya. Cara penggunaan tarif Reguler Ekspres adalah : Tentukan jenis pelayanan pengiriman yang akan dipergunakan sesuai dengan berat pengirimannya. Tarif dokumen $(1 \mathrm{~kg})$, tarif paket $(2 \mathrm{~s} / \mathrm{d} 99 \mathrm{~kg})$, tarif kargo $\left({ }^{3} 100 \mathrm{~kg}\right)$

b. Trucking Express adalah melalui transportasi darat dengan pelayanan cepat dan harga yang ekonomis dengan menggunakan 1 (satu) armada khusus atau tersendiri dan ditujukan pada pelanggan yang memiliki barang pengiriman dalam jumlah besar atau banyak maupun pelanggan yang menginginkan pengiriman dalam 1 (satu) angkutan.

c. Vehicle Expreess adalah melalui transportasi darat dengan pelayanan cepat dan harga yang kompetitif untuk pengiriman berbagai jenis kendaraan bermotor seperti : sepeda motor, jet ski, gokart, sepeda maupun ATV Motor. Tarif pengiriman ini diperhitungkan dengan berat sebagai berikut : sepeda motor kecil $(<250 \mathrm{cc}$ atau setara dengan $110 \mathrm{~kg}$ ), sepeda motor besar ( $3250 \mathrm{cc}$ atau setara dengan $300 \mathrm{~kg}$ ), Jet Ski (setara dengan $300 \mathrm{~kg}$ ), Gokart (setara dengan $110 \mathrm{~kg}$ ), sepeda (setara dengan $40 \mathrm{~kg}$ ), ATV Motor (setara dengan $200 \mathrm{~kg}$ ).

Untuk pengiriman alat-alat berat (bulldozer, excavator dll) maka sesuai ketentuan daerah yang berlaku wajib menggunakan pengawalan dalam hal polisi setempat.

Adapun alur proses Logistik adalah
Kirim / Delivery 
Tabel 1. Penjelasan Aktivitas Operasional.

\begin{tabular}{|c|c|}
\hline $\begin{array}{l}\text { TUJUAN } \\
\text { JABATAN }\end{array}$ & $\begin{array}{l}\text { KETERANGAN } \\
\text { Mermbuat perencanaan, pengelolaan dan monitoring } \\
\text { operasional yang berhubungan dengan kegiatan operasional area. }\end{array}$ \\
\hline \multirow{18}{*}{$\begin{array}{l}\text { TANGGUNG } \\
\text { JAWAB } \\
\text { UTAMA }\end{array}$} & RENCANA \\
\hline & $\begin{array}{l}\text { 1.Membuat perencanaan tahunan di area yang meliputi program kerja, anggaran keuangan, } \\
\text { sumber daya manusia, serta sarana dan prasarana yang digunakan sebagai pedoman dalam aktivitas. }\end{array}$ \\
\hline & $\begin{array}{l}\text { 2. Menyusun strategi operasional yang meliputi pelayanan pengiriman, penerimaan barang, } \\
\text { pembayaran, } \\
\text { administrasi lain terkait pengiriman untuk meningkatkan efektifitas dan efesiensi proses operasional di } \\
\text { area. }\end{array}$ \\
\hline & PELAKSANAAN \\
\hline & $\begin{array}{l}\text { 1. Mengelola aktivitas pengiriman, penerimaan barang, administrasi pengiriman, pembayaran untuk } \\
\text { memastikan kegiatan pengiriman yang dilakukan dapat memusakan customer dan sesuai dengan } \\
\text { standar pelayanan, }\end{array}$ \\
\hline & $\begin{array}{l}\text { 2. Mengelola aktivitas pengiriman dengan wilayah lain sehingga barang bisa tiba dan diterima sesuai } \\
\text { dengan pesanan. }\end{array}$ \\
\hline & 3. Menjalin hubungan baik dengan pihak ketiga yang terkait dengan kegiatan operasional. \\
\hline & KONTROL \\
\hline & $\begin{array}{l}\text { Memonitor pelaksanaan aktivitas operasional di are untuk mengevaluasi kinerja yang telah dicapai } \\
\text { serta merencanakan tindakan korektif dan prepentif terhadap hal-hal yang menyimpang dari } \\
\text { perencanaan, }\end{array}$ \\
\hline & RELASI KERJA \\
\hline & INTERNAL PERUSAHAAN \\
\hline & 1. Senior Manger: koordinasi funsi keungan, operasional,marketing dan HRD \\
\hline & $\begin{array}{l}\text { 2. Finance Accounting Manager: koordinasi aktivitas keuangan agar dapat mendukung kegiatan } \\
\text { operasional perusahaan termasuk melakukan proses pengeluaran uang, melakukan penagihan kepada } \\
\text { pelanggan sekaligus melakukan monitoring terhadap saldo piutang usaha. }\end{array}$ \\
\hline & $\begin{array}{l}\text { 3. Human Resources and General Affair (HRGA) Manager: koordinasi atas proses kepegawaian } \\
\text { seperti rekrutmen, training,kesehatan juga pengurusan perjalanan dinas karyawan seperti pemesanan } \\
\text { tiket dan hotel, memastikan semua kebutuhan karyawan akankebutuhan pekerjaan bisa terpenuhi. }\end{array}$ \\
\hline & $\begin{array}{l}\text { 4. Marketing Manager: koordinasi kegiatan sales dan marketing di area Kalaimantan, menjaga } \\
\text { hubungan dengan pelanggan. }\end{array}$ \\
\hline & 5. Operasional Manager: koordinasi kegiatan operasional agar dapat berjalan lancar. \\
\hline & EKSTERNAL PERUSAHAAN \\
\hline & $\begin{array}{l}\text { Pihak Ketiga/Customer: penerimaan barang, pengiriman barang, administrasi pengiriman dan } \\
\text { keuangan. }\end{array}$ \\
\hline \multirow{5}{*}{$\begin{array}{l}\text { MASALAH } \\
\text { DAN } \\
\text { TANTANGAN }\end{array}$} & $\begin{array}{l}\text { 1. Transaksi dalam jumlah besar baik pengiriman dalam kota maupun luar kota harus tetap di } \\
\text { monitoring dengan baik. Hal ini bertujuan untuk tetap mendapat customer untuk pengiriman barang di } \\
\text { are. }\end{array}$ \\
\hline & $\begin{array}{l}\text { 2. Kondisi area yang relatif berjauhan antar wilayah memberikan tantangan untuk tetap dapat } \\
\text { berkomunikasi dan berkoordinasi sehingga kegiatan operasional tetap dapat berjalan lancar. }\end{array}$ \\
\hline & 3. Kondisi area yang berjauhan membutuhkan strategi tersendiri untuk memonitor seluruh. \\
\hline & $\begin{array}{l}\text { 4. Mengenai anak buah dalam jumlah relatif besar dan karakteristik yang berdeda-beda, mulai dari } \\
\text { back office sampai lapangan. Hal ini membutuhkan skill interpersonal, komunikasi dan pendekatan } \\
\text { dalam proses operasional. }\end{array}$ \\
\hline & $\begin{array}{l}\text { 5. Menangani komplain yang cukup berat di limitnya sehingga membutuhkan } \\
\text { kesabaran,empati,namun sekaligus aset untuk dapat membantu customer mengatasi permasalahan } \\
\text { yang di hadapi. }\end{array}$ \\
\hline \multirow{3}{*}{ WEWENANG } & 1. Memberikan penilaian, teguran serta surat peringatan terhadap bawah. \\
\hline & 2. Memiliki limit authorized approval setiap unit \\
\hline & 3. Menyetujui pengeluaran uang yang menjadi limitnya. \\
\hline
\end{tabular}

Sumber: Hasil Pengolahan Data (2019) 
Adapun hasil obeservasi adalah

1.Penerimaan Barang

Tabel 2. Penerimaan Barang

\begin{tabular}{|c|c|c|c|c|c|c|c|c|}
\hline \multicolumn{9}{|c|}{ PENERIMAAN BARANG (2018) } \\
\hline \multirow{3}{*}{ BULAN } & \multicolumn{7}{|c|}{ FLEET : PAKET EXSPRESS } & \multirow[b]{3}{*}{ TOTAL (Rp) } \\
\hline & \multirow{2}{*}{ PIC } & \multicolumn{2}{|c|}{ REGULER } & \multicolumn{2}{|c|}{ TRUCKING } & \multicolumn{2}{|c|}{ VEHICLE } & \\
\hline & & Kg & $\mathbf{R p}$ & Kg & $\mathbf{R p}$ & Kg & $\mathbf{R p}$ & \\
\hline \multicolumn{9}{|l|}{2017} \\
\hline Januari & $\mathrm{ADM}$ & 368 & $4,232,000.00$ & 625 & $10,937,500.00$ & 259 & $6,604,500.00$ & $21,774,000.00$ \\
\hline Februari & $\mathrm{ADM}$ & 310 & $3,565,000.00$ & 789 & $13,807,500.00$ & 315 & $8,032,500.00$ & $25,405,000.00$ \\
\hline Maret & $\mathrm{ADM}$ & 370 & $4,255,000.00$ & 854 & $14,945,000.00$ & 289 & $7,369,500.00$ & $26,569,500.00$ \\
\hline April & $\mathrm{ADM}$ & 375 & $4,312,500.00$ & 763 & $13,352,500.00$ & 291 & $7,420,500.00$ & $25,085,500.00$ \\
\hline Mei & $\mathrm{ADM}$ & 391 & $4,496,500.00$ & 696 & $12,180,000.00$ & 295 & $7,522,500.00$ & $24,199,000.00$ \\
\hline Juni & $\mathrm{ADM}$ & 389 & $4,473,500.00$ & 839 & $14,682,500.00$ & 298 & $7,599,000.00$ & $26,755,000.00$ \\
\hline Juli & $\mathrm{ADM}$ & 297 & $3,415,500.00$ & 887 & $15,522,500.00$ & 295 & $7,522,500.00$ & $26,460,500.00$ \\
\hline Agustus & $\mathrm{ADM}$ & 401 & $4,611,500.00$ & 831 & $14,542,500.00$ & 294 & $7,497,000.00$ & $26,651,000.00$ \\
\hline September & $\mathrm{ADM}$ & 425 & $4,887,500.00$ & 932 & $16,310,000.00$ & 292 & $7,446,000.00$ & $28,643,500.00$ \\
\hline Oktober & $\mathrm{ADM}$ & 398 & $4,577,000.00$ & 795 & $13,912,500.00$ & 302 & $7,701,000.00$ & $26,190,500.00$ \\
\hline November & $\mathrm{ADM}$ & 395 & $4,542,500.00$ & 789 & $13,807,500.00$ & 307 & $7,828,500.00$ & $26,178,500.00$ \\
\hline Desember & $\mathrm{ADM}$ & 527 & $6,060,500.00$ & 813 & $14,227,500.00$ & 205 & $5,227,500.00$ & $25,515,500.00$ \\
\hline \multicolumn{9}{|l|}{2018} \\
\hline Januari & $\mathrm{ADM}$ & 329 & $3,783,500.00$ & 732 & $12,810,000.00$ & 213 & $5,431,500.00$ & $22,025,000.00$ \\
\hline Februari & $\mathrm{ADM}$ & 325 & $3,737,500.00$ & 763 & $13,352,500.00$ & 215 & $5,482,500.00$ & $22,572,500.00$ \\
\hline Maret & $\mathrm{ADM}$ & 301 & $3,461,500.00$ & 781 & $13,667,500.00$ & 225 & $5,737,500.00$ & $22,866,500.00$ \\
\hline April & $\mathrm{ADM}$ & 297 & $3,415,500.00$ & 785 & $13,737,500.00$ & 289 & $7,369,500.00$ & $24,522,500.00$ \\
\hline Mei & $\mathrm{ADM}$ & 267 & $3,070,500.00$ & 783 & $13,702,500.00$ & 277 & $7,063,500.00$ & $23,836,500.00$ \\
\hline Juni & $\mathrm{ADM}$ & 293 & $3,369,500.00$ & 908 & $15,890,000.00$ & 276 & $7,038,000.00$ & $26,297,500.00$ \\
\hline Juli & $\mathrm{ADM}$ & 309 & $3,553,500.00$ & 866 & $15,155,000.00$ & 251 & $6,400,500.00$ & $25,109,000.00$ \\
\hline Agustus & $\mathrm{ADM}$ & 321 & $3,691,500.00$ & 872 & $15,260,000.00$ & 310 & $7,905,000.00$ & $26,856,500.00$ \\
\hline September & $\mathrm{ADM}$ & 318 & $3,657,000.00$ & 879 & $15,382,500.00$ & 298 & $7,599,000.00$ & $26,638,500.00$ \\
\hline Oktober & $\mathrm{ADM}$ & 341 & $3,921,500.00$ & 752 & $13,160,000.00$ & 283 & $7,216,500.00$ & $24,298,000.00$ \\
\hline November & $\mathrm{ADM}$ & 329 & $3,783,500.00$ & 821 & $14,367,500.00$ & 292 & $7,446,000.00$ & $25,597,000.00$ \\
\hline Desember & $\mathrm{ADM}$ & 294 & $3,381,000.00$ & 839 & $14,682,500.00$ & 307 & $7,828,500.00$ & $25,892,000.00$ \\
\hline
\end{tabular}


2. Pengirimaan dan Penerimaan Uang

Tabel 3. Pengirimaan dan Penerimaan Uang

\begin{tabular}{|c|c|c|c|c|c|c|c|c|c|}
\hline \multirow[b]{3}{*}{ BULAN } & \multicolumn{6}{|c|}{ PROSES PENGIRIMAN BARANG } & \multicolumn{3}{|c|}{ PERMINTAAN UANG } \\
\hline & \multicolumn{3}{|c|}{ CHECKER } & \multicolumn{3}{|c|}{ PENENTUAN GUARD } & \multirow[b]{2}{*}{ PIC } & \multirow[b]{2}{*}{$\begin{array}{c}\text { DIKETAHU } \\
\text { I }\end{array}$} & \multirow[b]{2}{*}{$\begin{array}{c}\text { DISETUJU } \\
\text { I }\end{array}$} \\
\hline & PIC & $\begin{array}{c}\text { DIKETAHU } \\
\text { I }\end{array}$ & $\begin{array}{c}\text { DISETUJU } \\
\text { I }\end{array}$ & PIC & $\begin{array}{c}\text { DIKETAHU } \\
\text { I }\end{array}$ & $\begin{array}{c}\text { DISETUJU } \\
\text { I }\end{array}$ & & & \\
\hline \multicolumn{10}{|l|}{2017} \\
\hline Januari & SPV & - & - & SPV & - & - & SPV & $\mathrm{V}$ & $\mathrm{V}$ \\
\hline Februari & SPV & - & - & SPV & $\mathrm{V}$ & - & SPV & $\mathrm{V}$ & $\mathrm{V}$ \\
\hline Maret & SPV & $\mathrm{V}$ & - & SPV & - & - & SPV & $\mathrm{V}$ & $\mathrm{V}$ \\
\hline April & SPV & - & - & SPV & $\mathrm{V}$ & - & SPV & $\mathrm{V}$ & $\mathrm{V}$ \\
\hline Mei & SPV & $\mathrm{V}$ & - & SPV & - & - & SPV & $\mathrm{V}$ & $\mathrm{V}$ \\
\hline Juni & SPV & $\mathrm{V}$ & - & SPV & - & - & SPV & $\mathrm{V}$ & $\mathrm{V}$ \\
\hline Juli & SPV & - & - & SPV & $\mathrm{V}$ & - & SPV & $\mathrm{V}$ & $\mathrm{V}$ \\
\hline Agustus & SPV & - & - & SPV & - & - & SPV & $\mathrm{V}$ & $\mathrm{V}$ \\
\hline September & SPV & $\mathrm{V}$ & - & SPV & - & - & SPV & $\mathrm{V}$ & $\mathrm{V}$ \\
\hline Oktober & SPV & - & - & SPV & $\mathrm{V}$ & - & SPV & $\mathrm{V}$ & $\mathrm{V}$ \\
\hline November & SPV & - & - & SPV & - & - & SPV & $\mathrm{V}$ & $\mathrm{V}$ \\
\hline Desember & SPV & - & - & SPV & - & - & SPV & $\mathrm{V}$ & $\mathrm{V}$ \\
\hline \multicolumn{10}{|l|}{2018} \\
\hline Januari & SPV & - & - & SPV & - & - & SPV & $\mathrm{V}$ & $\mathrm{V}$ \\
\hline Februari & SPV & - & - & SPV & - & - & SPV & $\mathrm{V}$ & $\mathrm{V}$ \\
\hline Maret & SPV & $\mathrm{V}$ & - & SPV & - & - & SPV & $\mathrm{V}$ & $\mathrm{V}$ \\
\hline April & SPV & $\mathrm{V}$ & - & SPV & $\mathrm{V}$ & - & SPV & $\mathrm{V}$ & $\mathrm{V}$ \\
\hline Mei & SPV & $\mathrm{V}$ & - & SPV & - & - & SPV & $\mathrm{V}$ & $\mathrm{V}$ \\
\hline Juni & SPV & $\mathrm{V}$ & - & SPV & - & - & SPV & $\mathrm{V}$ & $\mathrm{V}$ \\
\hline Juli & SPV & $\mathrm{V}$ & - & SPV & - & - & SPV & $\mathrm{V}$ & $\mathrm{V}$ \\
\hline Agustus & SPV & - & - & SPV & - & - & SPV & $\mathrm{V}$ & $\mathrm{V}$ \\
\hline September & SPV & $\mathrm{V}$ & - & SPV & - & - & SPV & $\mathrm{V}$ & $\mathrm{V}$ \\
\hline Oktober & SPV & - & - & SPV & $\mathrm{V}$ & - & SPV & $\mathrm{V}$ & $\mathrm{V}$ \\
\hline November & SPV & - & - & SPV & - & - & SPV & $\mathrm{V}$ & $\mathrm{V}$ \\
\hline Desember & SPV & - & - & SPV & - & - & SPV & $\mathrm{V}$ & $\mathrm{V}$ \\
\hline
\end{tabular}

Sumber: Hasil Pengolahan Data (2019)

Berdasarkan hasil monitoring selama observasi yang dilakukan diketahui terdapat beberapa catatan dari eksternal auditor group yang menjadi action plan tahun berjalan.

Tabel 4. Action Plan Tahun Berjalan

\begin{tabular}{|c|l|l|}
\hline NO & \multicolumn{1}{|c|}{ UNIT } & \multicolumn{1}{c|}{ CATATAN AUDIT } \\
\hline 1 & KEUANGAN & $\begin{array}{l}\text { Berdasarkan pemeriksaan terhadap kinerja keuangan diketahui masih terdapat } \\
\text { pembayaran yang tidak terdapat bukti voucher prmbayaran. Hal ini terliha dari 10 dari 24 } \\
\text { sampel berkas transaksi keuangan. }\end{array}$ \\
\hline 2 & PENGIRIMAN & $\begin{array}{l}\text { Masih terdapat kelemahan kontrol terhadap proses pengiriman barang. Dimana terdapat } \\
\text { kesalahan lokasi dalam pengiriman sebanyak 18 dari 29 sampel berkas pengiriman }\end{array}$ \\
\hline 3 & WAREHOUSE & $\begin{array}{l}\text { Untuk unit ini sudah berjalan dengan baik dimana pencatatan penerimaan dan } \\
\text { pengeluaran barang menggunakan prinsip FIFO (first in first out) }\end{array}$ \\
\hline
\end{tabular}

Sumber: Hasil Pengolahan Data (2019) 
Identifikasi Masalah

Kasus yang terjadi adalah dibagian Fleet dimana prosedur yang berjalan sebagai berikut:

1. Bagian administrasi Fleet menerima pesanan pengiriman barang dari pelanggan.

2. Fleet Supervisor memeriksa jenis barang/unit apakah memerlukan pengawalan polisi atau tidak

3. Jika pengiriman barang/unit yang memerlukan pengawalan polisi maka Fleet Supervisor segera menyiapkan personil polisi.

4. Fleet Supervisor mengajukan permintaan uang muka kebagian Finance (Kasir) dengan mengisi form Cash Advance yang disetujui oleh Manager Operasional.

5. Kasir dengan persetujuan FA Manager akan mengeluarkan uang.

Indikasi kecurangan (Fraud)

1. Pembayaran secara tunai langsung kepada Fleet Supervisor

Praktek yang berjalan selama ini semua pembayaran diatas Rp 1 juta maka pembayaran akan ditransfer angsung kepada yang berhak tanpa melalui perantara.

Untuk pembayaran dibawah Rp 1 juta maka yang bersangkutan mengambil langsung kepada kasir, tidak diperkenankan melalui perantara kecuali dalam kondisi dan situasi tertentu dan ada persetujuan Senior Manager juga surat kuasa.

2. Muncul keluhan dari pelanggan melalui pihak Marketing bahwa biaya pengawalan Yang dibebankan perusahaan lebih besar dibanding perusahaaan lain
3. Adanya informasi lewat sms gelap bahwa biaya tersebut di mark up oleh Fleet Supervisor.

4. FA Manager sudah beberapa menyampaikan kepada Operasional Manager bahwa prosedur tersebut tidak sesuai dengan SOP yang berlaku, akan tetapi dengan alas an bahwa kegiatan operasional harus tetap berjalan maka pengeluaran uang tetap dilakukan.

5. Perubahan gaya hidup Fleet Supervisor

Dari karyawan lain didapat informasi bahwa yang bersangkutan mempunyai gaya hidup diluar profile dan penghasilan yang didapat. Ybs selalu menggunakan barang-barang ber-merk dan mempunyai 3 (tiga) buah mobil (Honda Freed, Honda City dan Mitsubshi Colt Diesel)

Kasus diatas terungkap jelas pada saat dilakukan klarifikasi dengan petugas polisi bersangkutan yang mengaku bahwa jumlah yang diterima hanya setengah $(50 \%)$ dari yang dibayarkan perusahaan

\section{HASIL DAN PEMBAHASAN}

Berdasarkan hasil laporan audit ekternal yang dilakukan, penulis melakukan analisa sederhana dengan membandingkan hasil observasi lapangan yang ada dengan table aktivitas operasional berdasarkan kasus yang terjadi. Data hanya berdasarkan unit yang ada di operation serta keuangan yang dijadikan dasar perbandingan hanya unit yang terkait.

Berdasarkan analisa yang dilakukan maka hasilnya dapat dilihat pada table sebagai berikut:

Tabel 5. Data Hasil Presentase Perbandingan

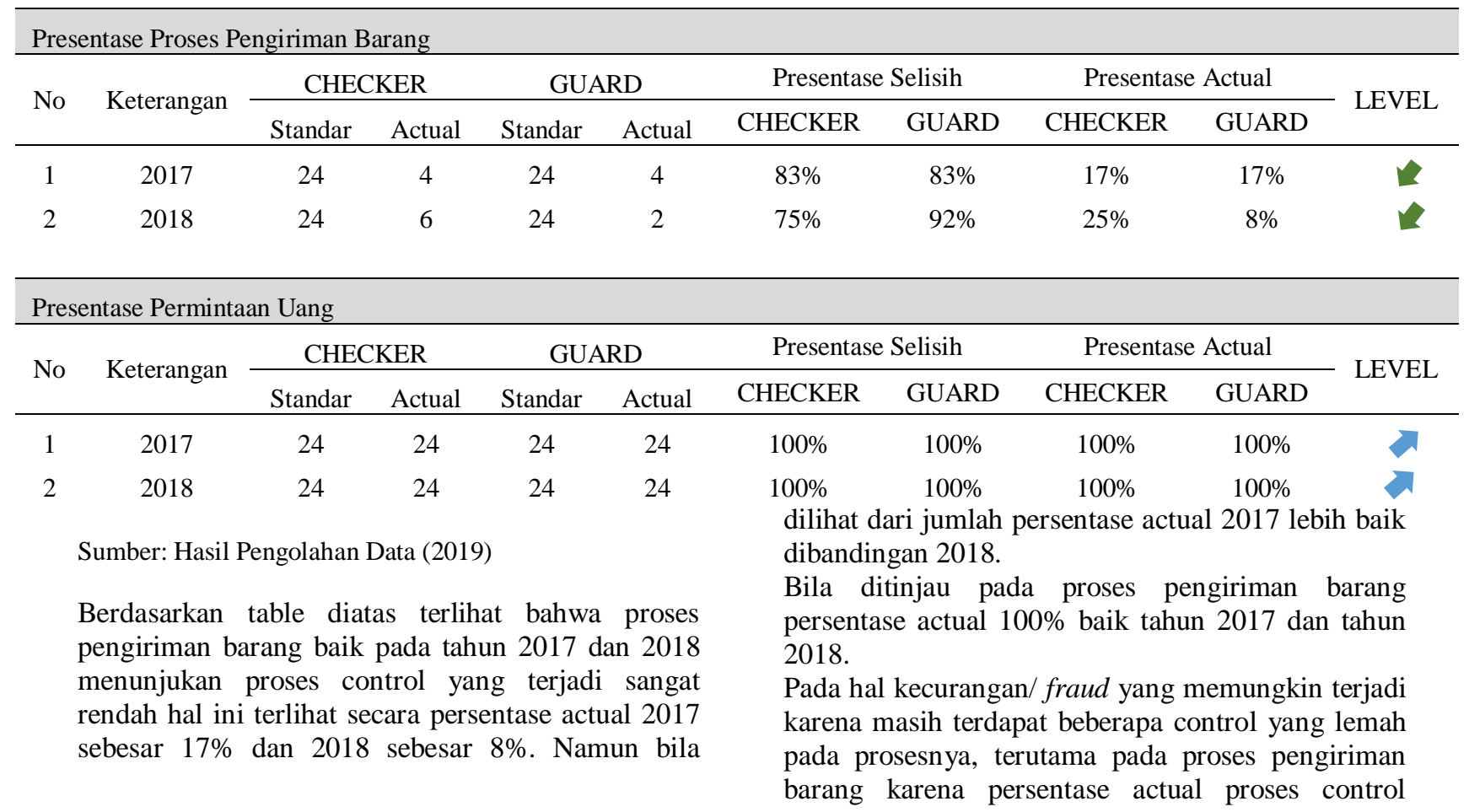


menunjukan angka yang rendah. Risiko yang timbul bersifat reputation risk dan financial risk. Risiko kan berpengaruh terhadap nama baik dan jumlah keuangan perusahaan berpotensi terdapat penambahan namun uang yang seharusnya disetorkan ke perusahaan namun disalah gunakan untuk kepentingan sendiri atau lapping.

Tabel 6. Data Control Level

\begin{tabular}{|c|c|c|c|c|c|c|}
\hline \multicolumn{7}{|c|}{$\begin{array}{c}\text { Indentifikasi Masalah vs } \\
\text { Presentase Actual }\end{array}$} \\
\hline \multirow{2}{*}{ No } & \multirow{2}{*}{ Keterangan } & \multicolumn{2}{|c|}{ Pengiriman Barang } & \multicolumn{2}{|c|}{ Permintaan Uang } & \multirow{2}{*}{ LEVEL } \\
\hline & & CHECKER & \multirow[t]{2}{*}{ GUARD } & CHECKER & \multirow[t]{2}{*}{ GUARD } & \\
\hline \multicolumn{5}{|c|}{ TAHUN 2017} & & \\
\hline 1 & $\begin{array}{l}\text { Administrasi } \\
\text { Fleet }\end{array}$ & $0.3 \%$ & $0.3 \%$ & $0.2 \%$ & $0.4 \%$ & HIGH \\
\hline 2 & $\begin{array}{l}\text { Fleet } \\
\text { Supervisor }\end{array}$ & $0.2 \%$ & $17 \%$ & $0.3 \%$ & $0.3 \%$ & HIGH \\
\hline 3 & Personil Polisi & $17 \%$ & $17 \%$ & $100 \%$ & $100 \%$ & LOW \\
\hline 4 & Cash Advance & $1 \%$ & $1 \%$ & $100 \%$ & $100 \%$ & MEDIUM \\
\hline 5 & Payment & $1 \%$ & $0.3 \%$ & $100 \%$ & $100 \%$ & MEDIUM \\
\hline \multicolumn{7}{|c|}{ TAHUN 2018} \\
\hline 1 & $\begin{array}{l}\text { Administrasi } \\
\text { Fleet }\end{array}$ & $0.3 \%$ & $0.3 \%$ & $0.2 \%$ & $0.4 \%$ & HIGH \\
\hline 2 & $\begin{array}{l}\text { Fleet } \\
\text { Supervisor }\end{array}$ & $0.2 \%$ & $8 \%$ & $0.3 \%$ & $0.3 \%$ & HIGH \\
\hline 3 & Personil Polisi & $25 \%$ & $8 \%$ & $100 \%$ & $100 \%$ & LOW \\
\hline 4 & Cash Advance & $1 \%$ & $1 \%$ & $100 \%$ & $100 \%$ & MEDIUM \\
\hline 5 & Payment & $1 \%$ & $0.3 \%$ & $100 \%$ & $100 \%$ & MEDIUM \\
\hline & $\begin{array}{l}\text { umber: Hasil Pengol } \\
\text { erdasarkan hasi } \\
\text { erdasarkan bagian } \\
\text { iketahui terdapat } \\
\text { hingga memiliki } \\
\text { isa terlihat pada } \\
\text { apervisor. Untu } \\
\text { enggunakan jas } \\
\text { ontrol yang dilak } \\
\text { enyalahgunaan ata } \\
\text { Intuk cash advan } \\
\text { ersifat moderat } \\
\text { etidaksesuain juga } \\
\text { engan demikian } \\
\text { ecurangan/fraud } \\
\text { ingsi control mas } \\
\text { ta. Bila dih } \\
\text { ecurangan/fraud } \\
\text { emungkinan bes } \\
\text { ibenarkan dengan } \\
\text { iatas. Dimana fle } \\
\text { nsur yang } \\
\text { ecurangan/fraud. }\end{array}$ & $\begin{array}{l}\text { dan control } \\
\text { hun } 2017 \text { serta } 2018 \\
\text { yang sangat rendah } \\
\text { cukup tinggi, hal ini } \\
\text { stasi fleet dan fleet } \\
\text { an guard yang } \\
\text { kepolisian dilihat } \\
\text { aik sehingga risiko } \\
\text { lain menjadi rendah. } \\
\text { ment control masih } \\
\text { enyalahgunaan dan } \\
\text { n masih ada. } \\
\text { mungkinan terjadi } \\
\text { skin terjadi karena } \\
\text { aksimal secara rata- } \\
\text { dengan indikasi } \\
\text { atau akan terjadi } \\
\text { nar. Dan hal ini } \\
\text { ng telah dijelaskan } \\
\text { or memiliki unsur- } \\
\text { sikan terjadinya }\end{array}$ & $\begin{array}{l}\text { Baik teo } \\
\text { kesimpul } \\
\text { 1. Adany } \\
\text { meleb } \\
\text { mence } \\
\text { kebutt } \\
\text { 2. Kesen } \\
\text { dan } \\
\text { menja } \\
\text { 3. Pengu } \\
\text { kecur: } \\
\text { ada pe } \\
\text { peruse } \\
\text { Hal in } \\
\text { bahwa } \\
\text { pelaku } \\
\text { dipind } \\
\text { Menjelas } \\
\text { penelitian } \\
\text { algoritma } \\
\text { untuk m } \\
\text { program } \\
\text { sehingga } \\
\text { ilmiah. }\end{array}$ & $\begin{array}{l}\text { Sawyer dan } \\
\text { sebagai berikı } \\
\text { kebutuhan, } \\
\text { kemampua } \\
\text { cara agar } \\
\text { annya. } \\
\text { atan ,dengan } \\
\text { dekatan deng } \\
\text { sesuatu yang } \\
\text { kapan , } \\
\text { an yang per } \\
\text { ku yang dikel } \\
\text { an si pelaku } \\
\text { nembuat pelak } \\
\text { ka terungkap } \\
\text { tidak dik } \\
\text { kan. } \\
\text { kronologis } \\
\text { prosedur p } \\
\text { Pseudocode } \\
\text { guji dan aku } \\
\text { enelitian ha } \\
\text { enjelasan ters }\end{array}$ & $\begin{array}{l}\text { e teori da } \\
\text { an gaya } \\
\text { nembuat } \\
\text { at tetap } \\
\text { venang ya } \\
\text { Operasion } \\
\text { mfaatkan } \\
\text { kejad } \\
\text { terjadi di } \\
\text { an tetapi ac } \\
\text { nutasi ke } \\
\text { rani meng. } \\
\text { kemungkin } \\
\text { kan teta } \\
\text { itian, term } \\
\text { tian (dal } \\
\text { lainnya), } \\
\text { data. De } \\
\text { didukung } \\
\text { dapat dite }\end{array}$ & $\begin{array}{l}\text { diambil } \\
\text { lup yang } \\
\text { pelaku } \\
\text { eemenuhi } \\
\text { dimiliki } \\
\text { manajer } \\
\text { pelaku, } \\
\text {-kejadian } \\
\text { rusahaan, } \\
\text { juga oleh } \\
\text { rah lain. } \\
\text { bil resiko } \\
\text { bahwa si } \\
\text { hanya } \\
\\
\text { kk desain } \\
\text { bentuk } \\
\text { agaimana } \\
\text { ipsi dari } \\
\text { referensi, } \\
\text { ha secara }\end{array}$ \\
\hline
\end{tabular}

\section{KESIMPULAN}

\section{Relevansi teori dengan contoh kasus kecurangan yang terjadi}

Teori-teori mengenai kecurangan sebagaimana telah diuraikan dalam Bab II merupakan jawaban apa dan mengapa kecurangan dilakukan.

Berdasarkan dari pembahasan masalah serta analisi kasus maka penulis dapat mengambil kesimpulan dan saran untuk menghindari terjadinya kembali kasur fraud tersebut. 
Kesimpulan

1. Terlalu percaya kepada rekan sekerja.,operasional Manager terlalu percaya kepada Fleet Supervisor sehingga selalu memberikan persetujuan tanpa melakukan cross check informasi lagi sehingga dimamfaatkan oleh pelaku untuk melakukan kecurangan.

2. Sistem komunikasi belum berjalan secara baik ,dari interview awal didapat informasi dari FA Manager bahwa ybs sudah beberapa kali mengingatkan Operation Manager mengenai adanya prosedur yang salah dalam proses pengeluaran biaya ini. Hal ini akan jauh lebih baik jika melibatkan senior manager sebagai pimpinan tertinggi di tempat tersebut.

3. Tidak adanya kejujuran, integritas dan loyalitas dari karyawan

Sistem yang paling baik sekalipun tidak dapat berjalan bilamana mental dan moral karyawan tidak baik

Saran yang dapat disampaikan dari penulis

1. Sosialisasi kembali SOP yang berlaku, FA Manager melakukan sosialisi kembali mengenai prosedur pembayaran atau pengeluaran uang sesuai ketentuan dan peraturan yang sudah ditetapkan.

2. Transparan biaya pengawalan, membuat tarif yang diketahui oleh semua bagian (keuangan, marketing dan operasional) sehingga meminimalisasi terjadinya mark up biaya

3. Pemberian sanksi yang jelas dan tegas, perusahaan belum memiliki sanksi yang mengatur secara jelas bagaimana menindak lanjuti kecurangan yang berlaku. Pada karyawan tertentu ada di keluarkan tetapi ada juga yang hanya di mutasi ke daerah lain.

4. Secara rutin setiap manajer melakukan kunjungan ke daerah-daerah untuk bertemu dengan bawahan nya, dengan melakukan kunjungan maka akan terjalin kedekatan karena karyawan merasa diperhatikan sehingga diharapkan bisa terjalin keakraban. Hal ini bisa mendorong karyawan untuk mau berbicara ke atasan masing-masing jika menemukan masalah baik mengenai urusan perusahaan maupun masalah lain.

5. Pemberian bantuan bagi karyawan yang membutuhkan,saat ini perusahaan tidak mempunyai peraturan mengenai pinjaman kepada karyawan. Mengingat masing-masing area mempunyai kas operasional masing-masing maka hal ini rawan terjadi kecurangan karena dalam keadaan terdesak seperti keluarga sakit, biaya anak sekolah akan meningkatkan tekanan bagi karyawan sehingga sangat mungkin akan melakukan kecurangan.

\section{REFERENSI}

Andi Martias. (2017). Interaksi pengalaman, indenpendensi, kompetensi, etika auditor dan insentif moneter terhadap hasil pemeriksaan. Konfrensi Nasional Ilmu Sosial Dan Teknologi, 1, 5-10. Retrieved from http://seminar.bsi.ac.id/knist/index.php/UnivB SI/issue/view/1/showToc

Blanchhard, G. . \& F. (2013). System Engineering And Analysis. (Prentice Hall, Ed.) (4th edisio). New Jaersy: Prentice Hall.

Hiro Tugiman. (2013). Auditor Internal Wajib Bersertifikat. Audit Internal YPAIA, 03(.), 2327.

Hogan, W. . (2014). How To Apply TQM To The Internal Audit Fuction. Internal Auditing, 9(Winter No.3), 3-14.

Lawrence B. Sawyer, JD, CIA, PA; Mortimer A. Dittenhofer, Ph.D.,CIA; James H. Scheiner, Ph.D., Sawyer's Internal Auditing, Salemba Empat, Jakarta 2006

Martias, A. (2017). Meningkatkan Kualitas Fungsi Audit Internal Melalui Total Quality Management. Simposium Nasional Ilmu Pengetahuan Dan Teknologi, 1, B 12-18. Retrieved from http://seminar.bsi.ac.id/simnasiptek/index.php/ simnasiptek-2017/article/view/151

Martias, A. (2018). Analisa Dampak Lemahnya Pengendalian Internal Sentra Kas PT. ALKHA atas Pilot Project Pengelolaan CDM Potensi Fraud. Seminar Nasional Inovasi Dan Tren (SNIT) 2108, 1, 1-8. Retrieved from http://seminar.bsi.ac.id/snit/index.php/snit2018/article/view/19

Onong Ichjana Efendy. (2014). Ilmu Komunikasi Teori dan Praktek. (CV. Remaja Karya Bandung, Ed.) (1st ed.). Jakarta, Indonesia: CV. Remaja Karya Bandung.

Soewarno Handaya Ningrat. (2010). Pengantar Ilmu Studi dan Manajemen. (CV Haji Masagung, Ed.) (Edisi 1). Jakarta, Indonesia: Gramedia.

Sukanto Reksohadiprojo. (1986). Organisasi Perusahaan. (BPFE Yogyakarta, Ed.) (Edisi 11). Yogyakarta: BPFE Yogyakarta.

T Hani Handoko. (1986). Ilmu Manajemen. (BPFE Yogyakarta, Ed.) (Edisi 5). Yogyakarta: BPFE Yogyakarta.

Wruck, H.K. and Jensen, M. . (2013). Science, Specific Knowledge, and Total Quality Management. Journal of Accounting and Economics, 18(3), pp.247-87, pp.73-79.

Yayasan Pendidikan Internal Audit (2008), Fraud Auditing

Yayasan Pendidikan Internal Audit (2008), Standar Profesi Audit Internal 


\section{PROFIL PENULIS}

Andi Martias SE, M.Si, Ak, QIA lahir Palembang, Sumatera Selatan, menyelesaikan SI di Universitas Islam Indonesia di Fakultas Ekonomi, Jurusan Akuntansi, S2 di Megister Sience Universitas Gadjah Mada Yogyakarta (UGM), Pendidikan Profesi Akuntansi di Universitas Sriwijaya Palembang (UNSRI) dan Qualified Internal Audit
(QIA) di Yayasan Pendidikan Internal Audit Jakarta (YPIA). Aktif sebagai dosen di Universitas Bina Sarana Informatika, praktisi di perusahaan dan aktif sebagai anggota Internal Auditor di YPIA Jakarta. 